Brit. J. Ophthal. (1956) 40, 510.

\title{
APPLIANCE
}

\section{AN ACCESSORY FOR THE OPERATING TABLE*}

BY

\section{H. CAMPBELL ORR \\ Wolverhampton}

All surgeons must at some time or other in the course of the more delicate operations have wished for something to give more stability to the hand or wrist. Professor Mercier at Tours uses an attachment at the head of the table which enables him to rest his arms and wrists when operating, but it is an expensive fitting and it was thought that something might be devised which was inexpensive and easily made. If it could be removed easily and taken to another hospital and fitted to any operating table this also would be an advantage.

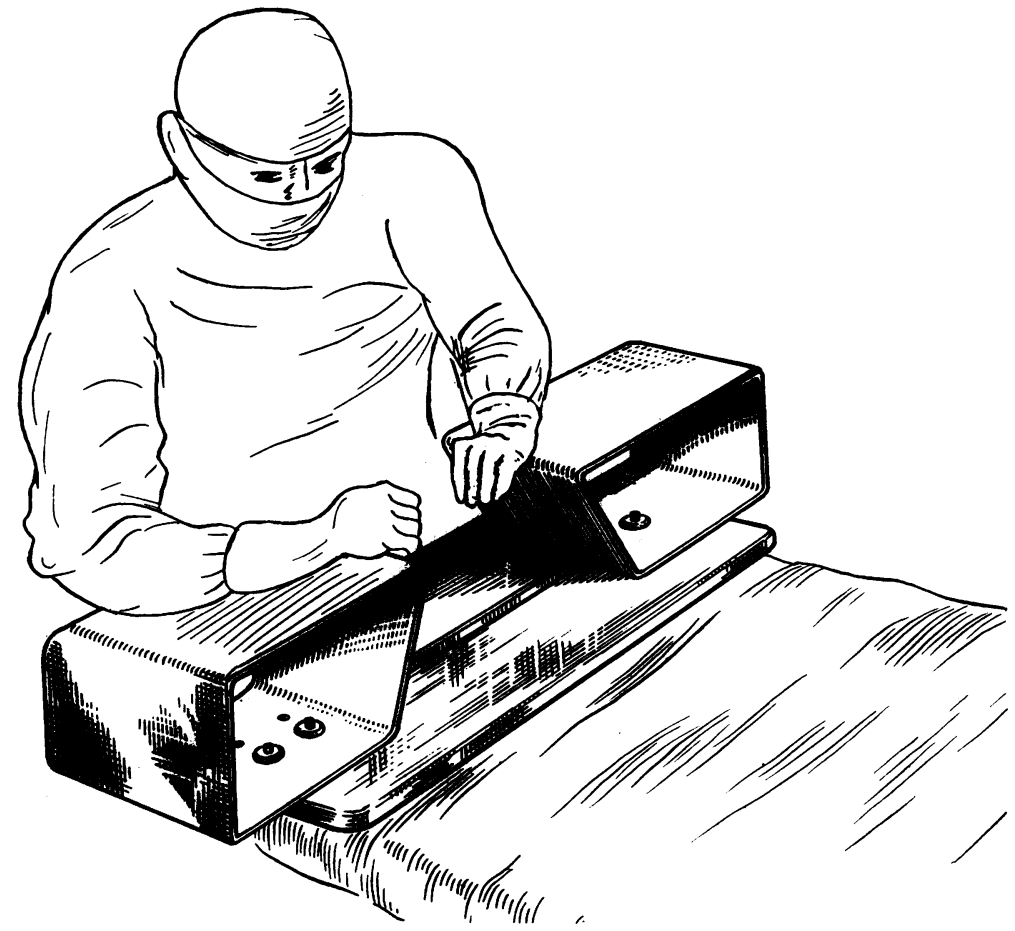

FIGURE.-Hand-rests in position at head of operating table.

* Received for publication April 4, 1956. 
With the assistance of the hospital carpenter, Mr. C. J. Taylor, and the helpful criticism of my house officer, Mr. C. R. Kanagasundaram, the device illustrated was made and has proved excellent. The prototype was made in wood and the final piece in aluminium.

The base board, which is made in plywood and covered with aluminium sheeting, 14 gauge, measures $24^{\prime \prime} \times 9^{\prime \prime} \times \frac{1}{2}$, , and a slot is cut in centre to allow small brass bolts to pass through it. A groove on the under surface allows the heads of the screws or bolts to move freely without catching in the sheets on the operating table, but the same object could be achieved by attaching a layer of rubber sheeting to the under surface of the base board.

The hand-rests measure $10^{\prime \prime} \times 7^{\prime \prime}$ across the top and are $5 \frac{1}{2}$ high. The upper edge is curved inwards to prevent linen catching on it. The base of each hand-rest is made 3 " narrower than the top, so that when the rests are brought up against the sides of the patient's head no pressure is put on the ears and the patient is quite comfortable. The height of the patient's head is adjusted by means of one or two sorbo rubber pads placed in the gap, and these act also as a pillow or cushion for the head.

The hand-rests covered with sterile towels are brought gently against the sides of the patient's head and then the screws inside the hollow box are tightened. This device has also proved useful when the operating theatre is short of staff, as it is a great advantage to be able to put down an instrument and then pick it up again without removing ones eyes from the field of operation.

The total cost including the carpenter's time was $£ 4$.

In addition to those named I am indebted to Mr. Mulverhill, charge-nurse in the operating theatre, for suggestions, and to Mr. J. Hepburn for the sketch of the apparatus. 